\title{
Use of in situ and airborne reflectance for scaling-up spectral discrimination of coral reef macroalgae from species to communities
}

\author{
Serge Andréfouët ${ }^{1,4, *}$, Claude Payri ${ }^{2,4}$, Eric J. Hochberg ${ }^{3}$, Chuanmin $\mathrm{Hu}^{1}$, \\ Marlin J. Atkinson ${ }^{3}$, Frank E. Muller-Karger ${ }^{3}$ \\ ${ }^{1}$ Institute for Marine Remote Sensing, College of Marine Science, University of South Florida, 140, 7th Av. South, \\ St Petersburg, Florida 33701, USA \\ ${ }^{2}$ Université de la Polynésie Française, Laboratoire Terre-Océan, BP 6570, Faaa-Aéroport, Tahiti, French Polynesia \\ ${ }^{3}$ University of Hawaii, Hawaii Institute of Marine Biology, PO Box 1346, Kanehoe, Hawaii 96744, USA \\ ${ }^{4}$ Present address: Institut de Recherche pour le Développement, BP A5, 98848 Nouméa cedex, New Caledonia
}

\begin{abstract}
In principle, a priori knowledge of organism-scale spectral signatures for key ecological end-members is a basic requirement for identifying coral reef benthic communities using hyperspectral remotely-sensed imagery. Spectral signatures of end-members are now relatively well known for predominant reef taxa (coral, algae) and for the background of the living communities (e.g. sediments). What remains unclear is whether the criteria for spectral discrimination between endmembers at the millimeter or centimeter scale remain valid when attempting to process images at several meters resolution. In other words, is it possible to scale-up spectral criteria of identification from species/organisms to communities? We address this issue with in situ and 'compact airborne spectrometer imager' (CASI) hyperspectral measurements of the tropical marine flora of 2 South Pacific Ocean coral reefs. Targets were the dominant algal species and communities encountered in the shallow (0 to $3 \mathrm{~m}$ ) barrier and fringing reefs of Moorea Island and the outer margin of the rim of Rangiroa Atoll (French Polynesia). Stepwise wavelength selection and linear discriminant analysis highlighted the key non-redundant wavelengths necessary to achieve good separation between the predefined ecological groups. Comparison of the wavelengths identified from in situ and airborne measurements allowed definition of a subset of common wavelengths that were robust to changes in spatial scale and still provided excellent discrimination and classification accuracy between the ecological groups. These results suggest that continuous spectral signatures acquired in situ at the centimeter scale can be used to select key discrete wavelengths for remote-sensing observations of communities at the meter scale despite the spatial heterogeneity in benthic cover and the resulting spectral mixing.
\end{abstract}

KEY WORDS: CASI - Remote sensing - Hyperspectral - Atmospheric correction - Macroalgae · Coral reef $\cdot$ Atoll $\cdot$ Moorea $\cdot$ Rangiroa

\section{INTRODUCTION}

Over the past $8 \mathrm{yr}$, our knowledge on the spectral reflectance of coral reef benthos has risen from virtually nil to an overwhelming abundance of spectral libraries, generally acquired using hand-held spectrometers that are convenient enough to be used in the field (Yamano et al. 2002, Hochberg et al. 2003, Kutser et al. 2003, Louchard et al. 2003). Using these spectral libraries, current remote-sensing research aims to unmix remotely-sensed community-scale or habitat-scale spectra to retrieve the percent cover of individual endmembers (live corals, dead corals, algae, sediments, etc.) at different depths (Hochberg \& Atkinson 2003, 
Hedley et al. 2004). The ultimate goal is to remotely sense coral reef 'health' by separating algae from live coral, or dead coral from live coral over large areas and quantifying their cover (e.g. Hochberg \& Atkinson 2000, Mumby et al. 2001). A less challenging goal is the identification of the main benthic communities contributing to the structure of the reefs in order to estimate, for instance, the extent of habitats of economically important species (Long et al. 1993, Andréfouët et al. 2004), or to budget biogeochemical processes (Andréfouët \& Payri 2001).

Knowledge of organism-scale spectral signatures for key ecological end-members is a basic requirement for identifying benthic communities and their status by hyperspectral remotely-sensed imagery (Clark et al. 2000, Hochberg \& Atkinson 2003). Spectral signatures of end-members are now relatively well known for primary reef benthos (coral, algae) and for the background of the living communities (e.g. sediments). The vast majority of these spectra represent the reflective properties of a few square centimeters of homogeneous tissue or substrate at best. Because remote-sensing pixels cover larger areas, and because reef endmembers form inherently mixed communities at these larger scales, it is unclear whether the criteria for spectral discrimination between end-members at the millimeter or centimeter scales hold when attempting to process images at several meters resolution. In other words, is it possible to 'scale-up' spectral criteria of identification?

It has previously been assumed that if a set of wavebands allows spectral discrimination between algae and coral at a few square centimeters, then the same set would be valid at larger spatial (and ecological) scales and for various sites of investigation. This hypothesis led to good results in Kaneohe Bay, Hawaii (Hochberg \& Atkinson 2000). However, its general validity is questionable, since benthic objects in coral reefs spatially aggregate to form a virtually infinite number of combinations of intricate heterogeneous 3-dimensional mosaics, even at a few square meters resolution. It is therefore very possible that criteria for discrimination between species of cyanobacteria, brown, green and red algae, corals, soft corals, sponges, and different types of sediments based on in situ measurements will not be optimal for all communities.

The study of spectral separability has 2 applications. (1) At the organism scale, non-destructive optical measurements may provide precise information on the physiological properties of the target and its adaptation to different environments (e.g. photoacclimation of Hydrolithon onkodes: see Payri et al. 2001). Different signatures may indicate different physiologies. (2) Knowledge on the spectral separability of benthic objects is useful for designing and optimizing coral reef remote-sensing applications (Atkinson et al. 2001). The need for prior identification of the discriminatory wavebands is still critical, despite the availability of hyperspectral sensors providing an almost continuous signal from 350 to $700 \mathrm{~nm}$ (the spectral domain most useful in shallow and subsurface waters). Indeed, the technical limitations of many airborne (and space) sensors necessitate an operational compromise between spatial resolution and spectral resolution. For instance, it is sometimes only possible to achieve sub-meter or meter-scale spatial resolution in the multispectral mode, not in the hyperspectral mode. Thus, preliminary knowledge of discriminatory wavebands is critical. Excluding wavebands that provide redundant information may also facilitate post-acquisition processing.

In this study, our goal was to assess the robustness of waveband selection using reflectance measurements at both organism and community levels. For this purpose, we used in situ species-level measurements $(\mathrm{cm}$ resolution) and airborne 'compact airborne spectrometer imager' (CASI) hyperspectral community-level measurements (meter resolution) from two shallow reefs in French Polynesia. We focused on the rich algal species and communities of these 2 reefs (Pichon 1985, Payri 1987). Algal cover is substantial, if not dominant, on many reefs worldwide, comprising various communities controlled by hydrodynamics, depth, light, substrate, water quality, or nutrient gradients. With the increasing number of reports of algal blooms, and of settlement and spread of invasive species in reefs (e.g. Russel \& Balazs 1994, Stiger \& Payri 1997), there is also a need to assess with precision whether spectral discrimination between algae species and between algae communities is possible. The detection of changes in reefs and reef health status will probably motivate many future applications, but economic objectives (e.g. biomass estimation of algae interesting for biotechnology applications) or fundamental objectives such as assessment of the coralline algae contribution to reef calcification (Payri 1997) also motivate our research. The feasibility of large-scale benthos assessment with a focus on algae is of interest for many ecologists.

Algae in temperate environments and seagrass in tropical environments have received some attention (Jakubauskas et al. 2000, Wittlinger \& Zimmerman 2000, Dekker et al. 2001 [review], Fyfe 2003), but previous hyperspectral studies in tropical coral reefs have preferentially targeted live, bleached and dead corals (Hedley \& Mumby 2002 [review], Minghelli-Roman et al. 2002, Hochberg et al. 2003). For coral reefs, several studies have presented spectral signatures of macroalgal species (Maritorena et al. 1994, Myers et al. 1999, Andréfouët et al. 2001, Lubin et al. 2001, Kutser et al. 2003, Karpouzli et al. 2004) or have considered algal morphotypes (fleshy, turf, encrusting) and groups 
(Phaeophyceae, Chlorophyceae and Rhodophyceae) (Hochberg et al. 2003), but very few studies have addressed the community level (Mumby et al. 1997, Hochberg \& Atkinson 2000, Purkis \& Pasterkamp 2004). In their review, Hedley \& Mumby (2002) pointed out that 'it is clear that intra-specific spectral variation is considerable in macroalgae, but currently there is insufficient information to assess the extent to which this compromises the spectral discrimination of species.' We agree that more data are needed for this important benthic compartment at the species and community levels, and have chosen algae species and communities to address the scaling problem.

\section{MATERIALS AND METHODS}

Study sites. We selected 2 reef configurations typical of Pacific Ocean reef flats, namely the carbonate atolls of the Tuamotu Archipelago and the volcanic islands of the Society Archipelago. These were selected because of their obvious differences, to cover 2 different configurations. Both are well-known research sites. These 2 environments represent the dominant shallow algae communities encountered in French Polynesia (Payri et al. 2000). Bays, rocky volcanic shorelines, estuaries, or deeper lagoon floors or outer slopes were not considered since these 2 reef flats represent the majority of the productive coral reef areas present in the South Pacific islands and atolls.

Site 1-Tivaru, Rangiroa: The Tivaru reef flat located on the northwestern side of Rangiroa atoll (Fig. 1) is very shallow (not more than $50 \mathrm{~cm}$ depth), which is typical for Pacific atoll-rim flats. It presents (1) a coralline algal crest dominated by Hydrolithon onkodes on the oceanic side, (2) a back reef with alternation of patches of fossil crest and pools of corals mixed with algae, and (3) a lagoon-facing pavement that is either bare with scattered coral heads, or encrusted by coralline algae and algal turf mainly composed of the geneculate coralline Jania adhearens, Amphiroa annulata and A. fragilissima. Fig. 2 illustrates the spatial structure of this section of the Rangiroa outer rim. Algal flora is dominated by $H$. onkodes, but 4 different algaedominated communities are recognizable (Table 1). We also include the different coral pavements in our analysis.

Site 2-Tiahura, Moorea: In contrast to the Rangiroa reef flat, Tiahura reef on the northwestern coast of Moorea Island (Fig. 1) provides a greater diversity and
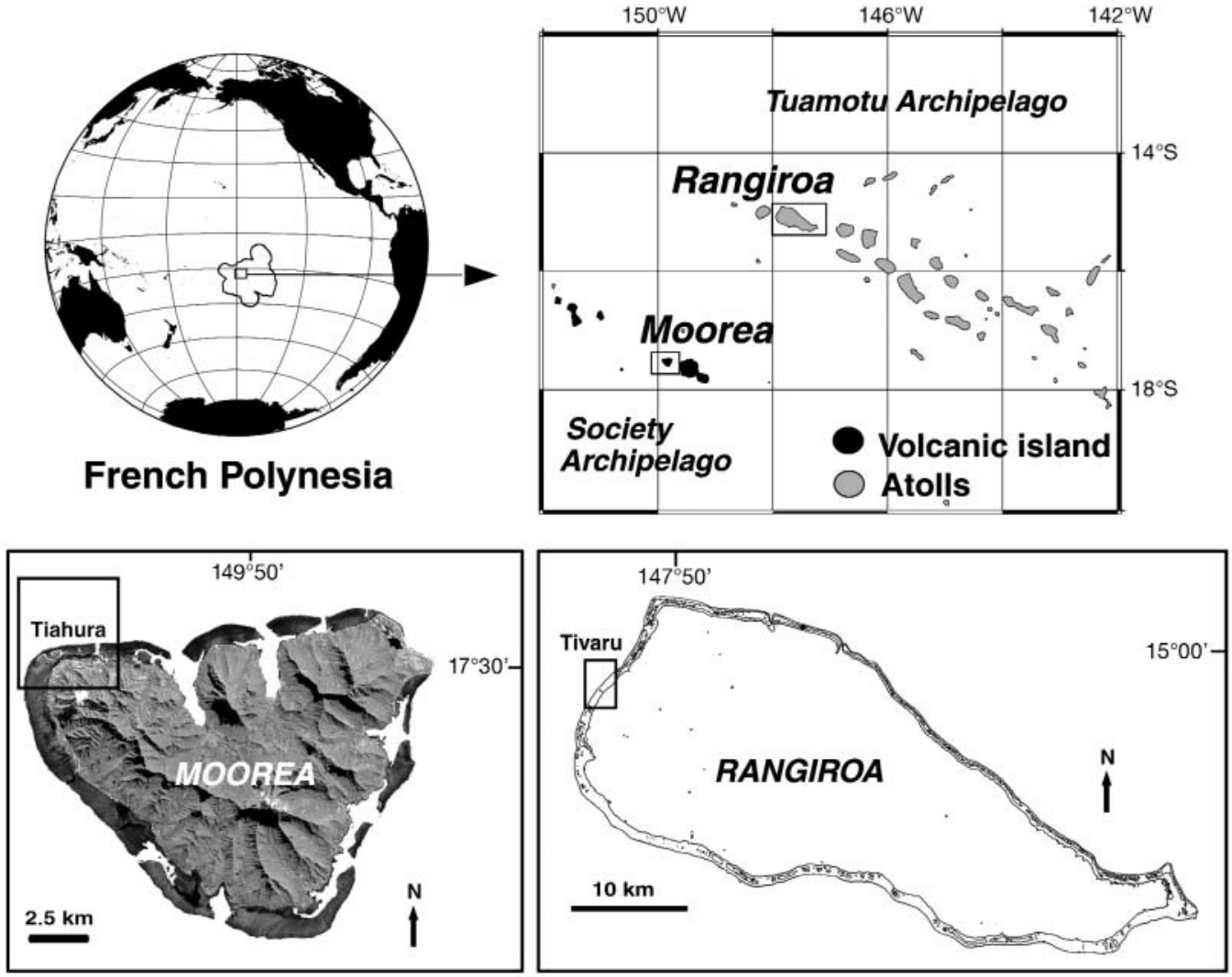

Fig. 1. Location of Moorea Island and Rangiroa Atoll 

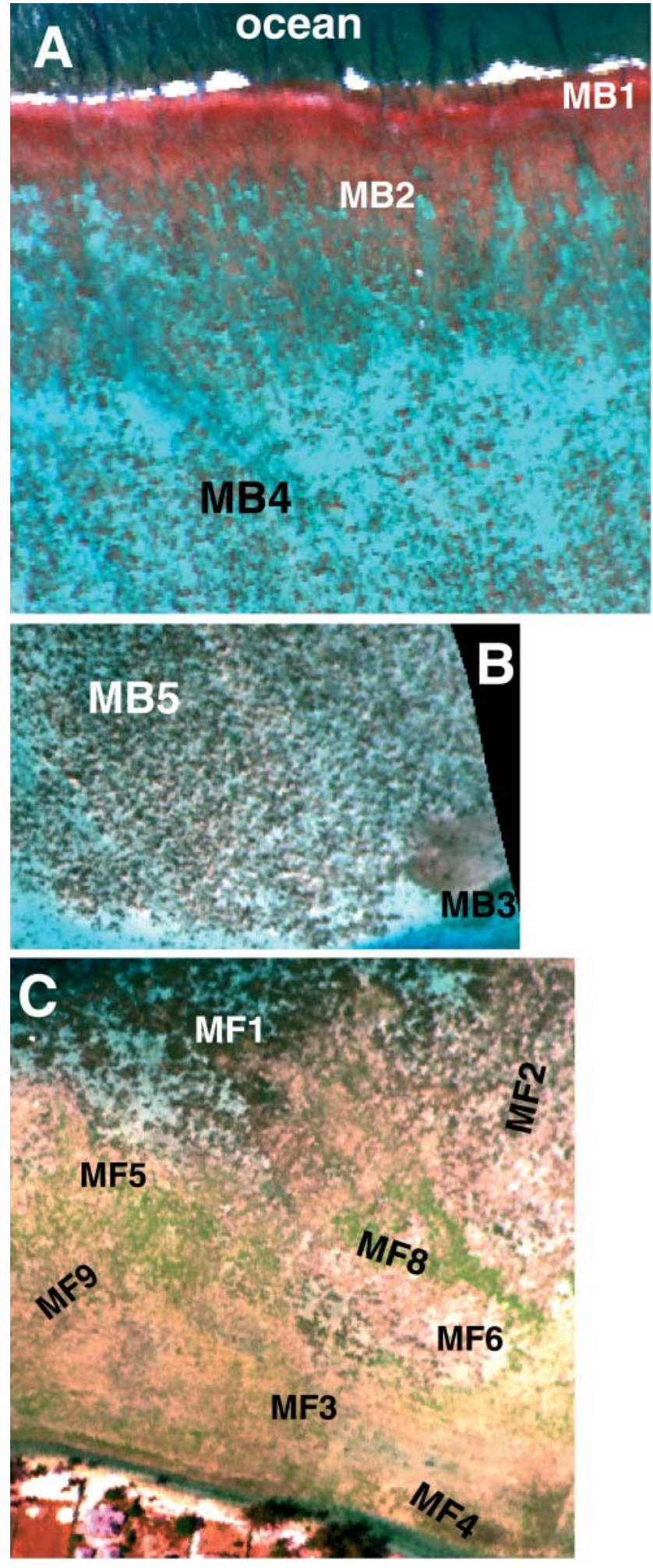

$100 \mathrm{~m}$

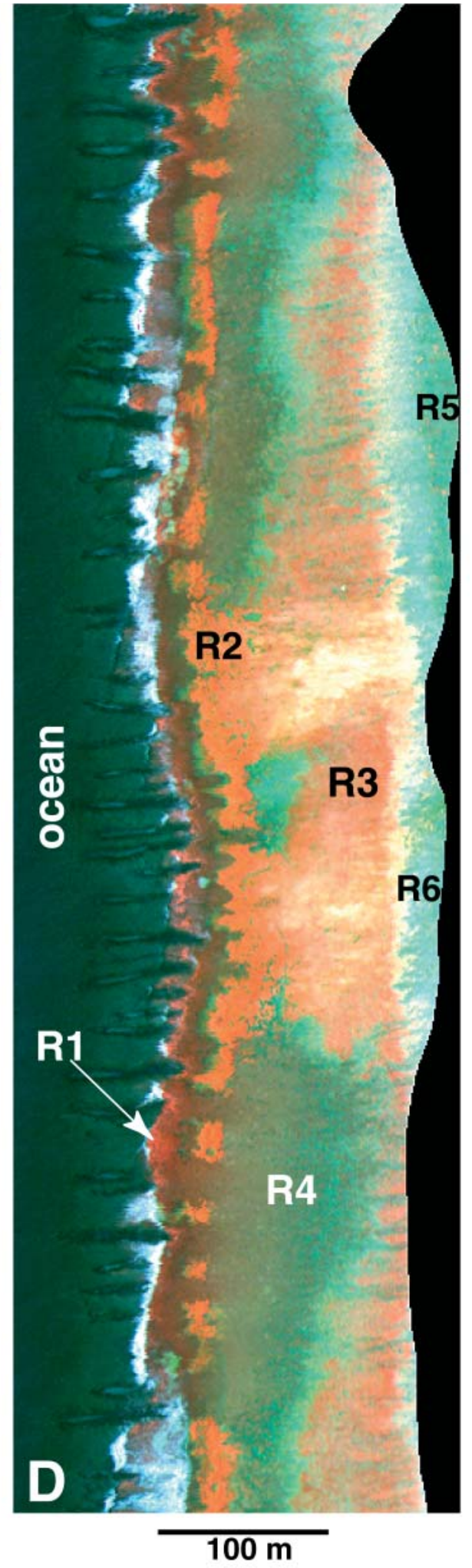

Fig. 2. Structure of studied reef sites and location of main algae communities; zones labeled as in Table 1. (A) Algal crest, backreef and large patches in Moorea barrier reef. (B) Small coral patches and Rhodoliths patch in Moorea barrier reef. (C) Moorea fringing reef communities. (D) Rangiroa coralline crest and back reef. Structure of each reef is revealed by these RGB (redgreen-blue) composites obtained with CASI bands: for $(\mathrm{A})$ and $(\mathrm{C}) \mathrm{R}=700, \mathrm{G}=554$ and $\mathrm{B}=435 \mathrm{~nm}$; for (B) $\mathrm{R}=674, \mathrm{G}=575$ and $\mathrm{B}=449 \mathrm{~nm} ;$ for(D) $\mathrm{R}=700, \mathrm{G}=562$ and $\mathrm{B}=436 \mathrm{~nm}$ 
Table 1. Algae present in each reef zone. Footnotes give composition of turfs and of rare algae on fringing reef (Rare f.a.)

\begin{tabular}{|c|c|c|c|c|c|}
\hline & & & & Dominant algae & Secondary algae \\
\hline \multirow[t]{6}{*}{ Rangiroa: } & Reef flat and crest & R1 & Crest & Hydrolithon onkodes & $\begin{array}{l}\text { Hydrolithon gardineri } \\
\text { Sporolithon spp. }\end{array}$ \\
\hline & & R2 & Fossil crest & $\begin{array}{l}\text { Rhodymeniales/Ceramiales assemblages } \\
\text { Hydrolithon onkodes }\end{array}$ & \\
\hline & & R3 & Lobophora variegata & $\begin{array}{l}\text { Lobophora variegata } \\
\text { Rhodymeniales/Ceramiales assemblages } \\
\text { Microdictyon spp. }\end{array}$ & Liagora ceranoides \\
\hline & & R4 & Coral & $\begin{array}{l}\text { Hydrolithon onkodes } \\
\text { Halimeda spp. } \\
\text { Microdictyon spp. } \\
\text { Hydrolithon onkodes }\end{array}$ & $\begin{array}{l}\text { Caulerpa pickerengii } \\
\text { Dictyota friabilis } \\
\text { Hydrolithon gardineri }\end{array}$ \\
\hline & & R5 & Pavement & $\begin{array}{l}\text { Jania adhaerens, Gelidium pusillum } \\
\text { on Hydrolithon onkodes }\end{array}$ & \\
\hline & & R6 & Bare pavement & & \\
\hline \multirow[t]{16}{*}{ Moorea: } & Barrier reef & MB1 & Crest & $\begin{array}{l}\text { Turbinaria ornata } \\
\text { Sargassum sociale } \\
\text { Sargassum mangarevense }\end{array}$ & $\begin{array}{l}\text { Amphiroa fragilissima } \\
\text { Jania adhaerens } \\
\text { Laurencia flexilis } \\
\text { Hydrolithon onkodes } \\
\text { Mastophora pacifica } \\
\text { Mesophyllum erubescens } \\
\text { Caulerpa webbiana } \\
\text { Chlorodesmis fastigiata } \\
\text { Codium geppii } \\
\text { Dictyosphaeria cavernosa } \\
\text { Dictyota hamifera }\end{array}$ \\
\hline & & MB2 & Back-crest & $\begin{array}{l}\text { Sargassum sociale } \\
\text { Sargassum mangarevense } \\
\text { Turbinaria ornata }\end{array}$ & $\begin{array}{l}\text { Amphiroa spp. } \\
\text { Jania spp. } \\
\text { Mesophyllum erubescens } \\
\text { Boodlea kaeneana } \\
\text { Chlorodesmis fastigiata } \\
\text { Halimeda spp. } \\
\text { Microdictyon umbilicatum } \\
\text { Dictyopteris repens } \\
\text { Dictyota hamifera } \\
\text { Lobophora variegata }\end{array}$ \\
\hline & & MB3 & Rhodolith patch & $\begin{array}{l}\text { Neogoniolithon frutescens } \\
\text { Hydrolithon reinboldii } \\
\text { Anabaena torulosa }\end{array}$ & \\
\hline & & MB4 & Large patches & $\begin{array}{l}\text { Sargassum mangarevense } \\
\text { Turbinaria ornata } \\
\text { Amansia rhodantha } \\
\text { Turf }^{\mathrm{a}}\end{array}$ & $\begin{array}{l}\text { Actinotrichia fragilis } \\
\text { Galaxaura fasciculata } \\
\text { Gelidiopsis spp. } \\
\text { Hydrolithon onkodes } \\
\text { Lithophyllum flavescens } \\
\text { Lithophyllum insipidium } \\
\text { Lithophyllum kotschyanum } \\
\text { Halimeda incrassata } \\
\text { Halimeda minima } \\
\text { Neomeris vanbosseae } \\
\text { Valonia fastigiata } \\
\text { Ventricaria ventricosa } \\
\text { Lobophora variegata }\end{array}$ \\
\hline & & MB5 & Small patches & $\begin{array}{l}\text { Turbinaria ornata } \\
\text { Sargassum mangarevense } \\
\text { Dictyota spp. }\end{array}$ & $\begin{array}{l}\text { Halimeda incrassata } \\
\text { Hydrolithon onkodes } \\
\text { Lithophyllum spp. turf } \\
\text { Gelidiopsis spp. }\end{array}$ \\
\hline & & MB6 & Pavement & & $\begin{array}{l}\text { Valonia aegagropila } \\
\text { Turbinaria ornata } \\
\text { Dictyota divaricata }\end{array}$ \\
\hline & Fringing reef & MF1 & Large channel patches & $\begin{array}{l}\text { Turf }^{\mathrm{a}} \\
\text { Turbinaria ornata }\end{array}$ & $\begin{array}{l}\text { Rare f.a. }{ }^{\mathrm{b}} \\
\text { Galaxara filamentosa }\end{array}$ \\
\hline & & MF2 & Compact, small, dead patches & $\begin{array}{l}\text { Turf a } \\
\text { Turbinaria ornata }\end{array}$ & Rare f.a. ${ }^{b}$ \\
\hline & & MF3 & Micro-atolls & $\begin{array}{l}\text { Padina boryana } \\
\text { Halimeda incrassata } \\
\text { Hydrolithon onkodes } \\
\text { Acanthophora spicifera } \\
\text { Turbinaria ornata }\end{array}$ & Rare f.a. ${ }^{b}$ \\
\hline & & MF4 & Halimeda spp. complex & Halimeda opuntia & Acanthophora spicifera \\
\hline & & MF5 & Sand rubble with Padina & $\begin{array}{l}\text { Padina boryana } \\
\text { Dictyota divaricata }\end{array}$ & $\begin{array}{l}\text { Hydrolithon reinboldii } \\
\text { Halimeda incrassata }\end{array}$ \\
\hline & & MF6 & Sand with Cyanobacteria & Phormidium spp. & Halimeda incrassata \\
\hline & & MF7 & Sand and rubble & & Hydrolithon reinboldii \\
\hline & & MF8 & Boodlea spp. bloom & Boodlea kaeneana & \\
\hline & & MF9 & Mixed fringing community & $\begin{array}{l}\text { Padina boryana } \\
\text { Halimeda opuntia } \\
\text { Acanthophora spicifera } \\
\text { Boodlea kaeneana } \\
\text { Halimeda incrassata }\end{array}$ & \\
\hline & & MF10 & Grazed turf on dead structures & $\begin{array}{l}\text { Turf }^{\mathrm{a}} \\
\text { Hydrolithon onkodes }\end{array}$ & $\begin{array}{l}\text { Padina boryana } \\
\text { Turbinaria ornata }\end{array}$ \\
\hline
\end{tabular}


patchiness of communities, habitats and ecological niches. The composition and dynamics of the algae community of Tiahura reef have been well studied (Payri 1987, 1997, Gattuso et al. 1997). In shallow areas $(<2 \mathrm{~m})$ encountered along the $800 \mathrm{~m}$ of reef from the shore to the algal crest, we observed 6 zones on the barrier reef (Fig. 2A,B) and 10 zones on the fringing reef (Fig. 2C) (Table 1). On the fringing reef, the main algal zones were the summit of the large coral heads at the edge of the channel, heterogeneous assemblages of various algae (mostly Padina boryana, Halimeda spp., Acanthophora sp.), different zones of dead structures (continuous coral framework and isolated microatolls) covered partly by turf algae and diverse assemblages, sandy areas rich in cyanobacteria, large Padina boryana and Halimeda incrassata beds close to shore, and sand/rubble zones. Moreover, a bloom of the green algae Boodlea kaeneana occurred during the acquisition of CASI data. On the barrier reef, the main algal zones were the belt of brown algae Turbinaria ornata and Sargassum mangarevense along the crest, the heterogeneous coral-algae back-reef framework, various zones of coral patches of different sizes and densities, zones of accumulation of the coralline rhodolithes Neogoniolithon frutescens and Hydrolithon reinboldii (overgrown by the cyanobacterium Anabaena torulosa at the time of the surveys), and areas of bare pavement with scattered brown algae.

Acquisition of in situ reflectance spectra of representative algae. There are 425 taxa of benthic marine algae inventoried in French Polynesia (Payri \& DeN'Yeurt 1998). Collection of in vivo or in vitro reflectance spectra for each of the species in the coral reef environment would be an unjustified and daunting task. Reflectance spectra are likely to be similar for many of these species because of their similar pigmentations (Beach et al. 1997). Also, such a task would be irrelevant from a remotesensing standpoint, since a large number of taxa are rare, hidden in crevices or spatially imbricate over a few square centimeters. Therefore, we selected a priori the most conspicuous and abundant species in the 2 reefs (Table 2) and insured that the Cyanophyceae, Phaeophyceae, Chlorophyceae and Rhodophyceae were all represented. We also included substrata (dead Porites spp., pavement, rubble) colonized by algal turfs. The algal turf sampled was a complex assemblage of filamentous forms including mainly red algae such as
Ceramiales (Polysiphonia spp., Ceramium spp., Corallophila apiculata, Herposiphonia spp.), Rhodymeniales (Gelidiopsis spp., Coelothrix irregularis, Champia spp.), the brown algae Sphacelaria spp. and the green alga Enteromorpha clathrata.

Hochberg \& Atkinson (2000) provided a scheme to measure radiance reflectance and assess benthos spectral separability. Underwater in situ reflectance $(R)$ spectra were measured on Rangiroa and Moorea in April 1999 using the same instrument and protocol detailed in Hochberg \& Atkinson (2000) and Hochberg et al. (2003). Briefly, using an Ocean Optics S2000, we measured the upwelling radiance of the target, and then normalized the result by the upwelling radiance measured from a lambertian Spectralon plaque of known reflectance $(10 \%)$. If we assume that the benthic target is also lambertian, this ratio provides the reflectance $R$. Both measurements were obtained within 2 to $3 \mathrm{~s}$. For some algae, taxa that could not be measured in the field in French Polynesia for diverse reasons (e.g. battery failure, unsuitable conditions), we included spectra from Palau, Micronesia (Table 2), measured in July 2000 following the same methods. Reflectance spectra were filtered using the Savitski-Golay algorithm and resampled at $2 \mathrm{~nm}$ spectral resolution (for details see Hochberg et al. 2003).

Table 2. Algae species selected for in situ reflectance measurements and their locations. Zones as in Table 1 and Fig. 2

\begin{tabular}{|ll|}
\hline Zone & Algae \\
\hline Rangiroa & \\
R5 & Jania adhaerens, Gelidium pusillum on \\
R1 & Hydrolithon onkodes \\
R3 & Hydrolithon onkodes \\
R2 & Lobophora variegata \\
R3 & Rhodymeniales \\
Moorea & Rhodymeniales and Lobophora variegate complex \\
MB2 & Sargassum mangarevense \\
MB2, MB4, MF1 & Turbinaria ornata \\
MB3 & Neogoniolithon frutescens, Hydrolithon reinboldii, \\
& Anabaena torulosa complex \\
MB4 & Lithophyllum flavescens \\
MB4 & Lithophyllum insipidium \\
MB4 & Hydrolithon onkodes \\
MF8 & Boodlea kaeneana \\
MF5 & Padina boryana \\
MF3 & Acanthophora spicifera \\
& Ceramium spp., Polysiphonia spp. turf complex \\
MB4, MF1 & Lophosiphonia spp., Heterosiphonia spp., Champia spp. \\
MF10 & Sphacelaria spp., Enteromorpha clathrata \\
Palau & Grazed turf \\
& \\
& Halimeda spp. \\
& Dictyota spp. \\
\hline
\end{tabular}


A total of 14 groups of in situ reflectance spectra (overall total $=616$ ) were obtained and processed in overall 1999, including individual algae species and complexes that could not be measured separately (Table 2).

Acquisition and processing of airborne CASI data. CASI images were acquired in May 1998 for Rangiroa and in November 1998 for Moorea. For each of the sites, several modes were used, providing various combinations of spectral and spatial resolution. Here, we considered the hyperspectral data acquisitions. These consisted of 21 bands evenly distributed between 400 and $700 \mathrm{~nm}$ for Moorea at $1 \mathrm{~m}^{2}$ spatial resolution, and 54 bands evenly distributed between 400 and $700 \mathrm{~nm}$ for Rangiroa at $2.7 \mathrm{~m}^{2}$ spatial resolution. We traded a lower spatial resolution for a better spectral resolution for Rangiroa because the coral community cover was less heterogenous. Flight altitude was 500 m. Weather conditions were ideal, with clear sky and no wind. There were small waves breaking along the reefs, but the crests were not completely obscured by foam. The Rangiroa crest was exceptionally calm during data acquisition; community description and groundtruthing (Fig. 2) were made simultaneously or a few days after the overflight.

CASI images were acquired and pre-processed by Hyperspectral Data International. CASI calibration was made by the ITRES company on an annual basis. The accuracy of radiometric calibration of the CASI is estimated to be $\pm 2 \%$ from 470 to $700 \mathrm{~nm}$ and $\pm 5 \%$ between 400 and $470 \mathrm{~nm}$ (Babey \& Soffer 1992). We extracted 230 total at-sensor radiance spectra $\left(L_{t}\right)$ from 16 locations in Moorea and 182 spectra from 14 locations in Rangiroa (Table 1). Each location represented a different community in Moorea. In Rangiroa, several community types were represented in multiple locations, providing duplicates and some mixed zones as well.

To transform the total radiance spectra into remotesensing reflectance $\left(R_{r s}\right)$, it is necessary to remove the reflected sky radiance and atmospheric effects and normalize by the downwelling irradiance (Mobley 1999, Toole et al. 2000, Hu \& Carder 2002). Thus

$$
R_{r s}=\frac{L_{t}-L_{s k y}-L_{a t m}}{t E_{d}}
$$

and

$$
L_{s k y} \approx t \rho \frac{E_{d s}}{r}
$$

where $L_{t}$ is the total at-sensor radiance, $L_{s k y}$ is the radiance accounting for the reflected sky light, $L_{a t m}$ is the atmospheric path radiance (light scattered to the sensor before reaching the sea surface), $t$ is the diffuse transmittance from the sea surface to the sensor, $\rho$ is the sea surface Fresnel reflectance, $E_{d}$ is the down- welling irradiance above the water surface, $E_{d s}$ is the diffuse component of $E_{d}$, and $r$ is the ratio between $E_{d s}$ and nadir sky radiance. $L_{a t m}$ and $t$ were computed using 6S software (Vermote et al. 1997). $\rho$ was set at 0.02 taking the incident viewing angle (note that this incident angle is not the solar angle, but the nadir sky angle, i.e. $0^{\circ}$ ) and calm sea surfaces into consideration. $E_{d}$ and $E_{d s}$ were taken from the spectral solar irradiance model of Gregg \& Carder (1990) after spectral binning to match CASI wavebands, and account for the extra-terrestrial irradiance attenuation due to Rayleigh and aerosol scattering, oxygen, ozone and watervapor absorption. Here, typical values for oceanic atmospheres have been used. To estimate $L_{s k y}$, we used the ratio $r$ of Aas \& Hokedal (1999). These authors provided $r$ for only 7 bands, thus we interpolated to retrieve the sky radiance between 400 and $700 \mathrm{~nm}$.

Statistical analysis of in situ and airborne spectra. Our goal was to characterize the spectral separability between benthic objects. Thus we applied well-known methods (Rencher 1995) to identify the key spectral bands and build linear discriminant functions (Hochberg \& Atkinson 2000, Karpouzli et al. 2004).

To determine which wavelength best separates the algal groups at species or community levels, we used the technique of stepwise selection of wavelength (SSW) and discriminant function analysis (DFA), detailed in Rencher (1995) and Hochberg \& Atkinson (2003). SSW discarded the wavelengths that were redundant for separating the predefined groups (Renche 1995). Individual wavelengths were selected based on partial p-values resulting from successive multivariate partial F-tests. We considered only wavelengths significant at $\mathrm{p}<0.05$. For the in-situ spectra, nonredundant wavelengths too close together for a remotesensing application were merged to provide a separation of at least $8 \mathrm{~nm}$ between wavelengths. In contrast to Hochberg \& Atkinson (2000), we did not discard wavelengths $>600 \mathrm{~nm}$ because water depth was not considered a limiting factor in this study, since most algae communities were in shallow reef flats $(0$ to $1 \mathrm{~m}$ depth in Rangiroa, 0 to $3 \mathrm{~m}$ in Moorea). These nonredundant wavelengths were used to build the linear discriminant functions (LDF) that best separated the different algal groups (Rencher 1995). Then, to visualize the actual discrimination operated by the linear discriminant functions, we projected individual spectra into the planes that best separated the predefined groups.

$R$ and $R_{r s}$ spectra from Rangiroa and Moorea were both analyzed with the SSW and DFA methods.

Scaling of spectral discrimination from species to community scale. The non-redundant wavelengths identified from in situ and CASI measurements by SSW were compared to identify a subset of common 
wavelengths. We assumed that wavelengths emerging from both in situ and CASI data would be sufficiently robust for a change in spatial and ecological scales, and that the other wavelengths could be discarded. In addition, the set of common wavelengths would be sufficiently robust for a change in measurements, since in situ data are radiance reflectance and airborne data are remote-sensing reflectance. To test this hypothesis, we used these common wavelengths to conduct a new DFA analysis of the CASI data and to observe the degradation in the classification compared to the DFA analysis conducted with the full set of non-redundant CASI wavelengths. For Moorea, where all species are encountered, we used the 616 in situ spectra available, while for Rangiroa we used only the local spectra, since algae are much more specific on the atoll crest and reef flat. The analysis is summarized in Fig. 3.

Classification accuracy. To quantify the loss of discrimination when using a subset of wavelengths, we assessed the accuracy of the classifications for the different groups of communities or algae. To avoid bias in assessing classification accuracy, especially for small sample sizes, it is necessary to have a set of training data, which are used to construct the classification rule, and a set of validation data used to evaluate the rule. Typically, a complete data set is split into 2 roughly equal parts, with one part used for training and the other for validation. However, partitioning the sample in this manner has at least 2 disadvantages. First, it requires large samples that may not be available (as in our case); second, it does not evaluate the classification function used in practice, i.e. the estimate of error based on half the sample might vary considerably from that based on the entire sample.

In this study, we employed an improved version of the sample-splitting procedure termed 'the holdout method' (also called cross-validation) (Rencher 1995). With the holdout method, all but 1 observation is used to compute the classification rule, and this rule is then used to classify the omitted observation. This procedure is repeated for each observation, so that for a sample size of $\mathrm{N}$, each observation is classified by a rule based on the other $\mathrm{N}-1$ observations. Withholding a single spectrum from the computation of a classification rule means that the rule is not biased by the variability engendered by that spectrum. Each time a different spectrum is withheld, the classification rule is independent from that spectrum, and each

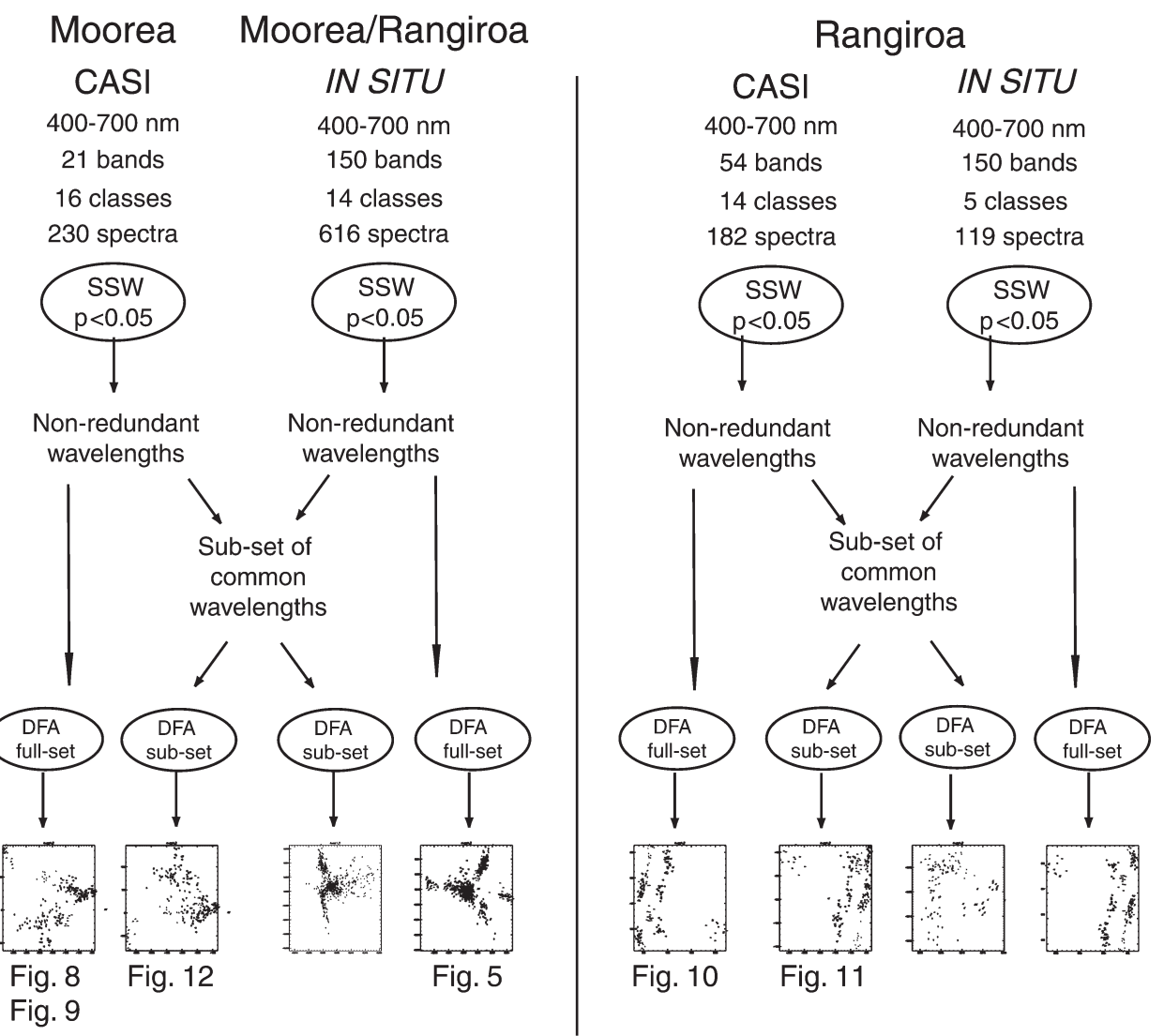

Fig. 3. Diagrams summarizing in situ and CASI data and their analysis for full set and subset of wavelength. DFA: discriminant function analysis; SSW: stepwise selection of wavelength 
newly computed rule is independent from all others. Although computationally more demanding, the holdout method has the advantage that, with only a single spectrum withheld, the classification rule is as close as possible to the rule that would be built using all spectra in the data set, thus minimizing the variance in the error rate estimate.

Classification results are in the form of an error matrix that shows how the spectra from one reference class are attracted to other classes, and how a reference class attracts spectra from other classes. A summary is provided by the overall accuracy, which is simply the ratio of correctly classified spectra to the total number of spectra.

\section{RESULTS}

\section{In situ reflectance and species level discrimination}

The differences between the mean reflectances of the main algae species are shown in Fig. 4 for Moorea and Rangiroa. Rubble, pavement, turfs and coralline spectra acquired on Moorea are available elsewhere (Andréfouët et al. 2001). The full set of in situ reflectance spectra highlights the continuum of algae color encountered in the field (inset in bottom graph of Fig. 4). Generally, the coralline and red algae covering Rangiroa reef flat provide brighter and less diverse spectra than the dominant brown and green algae of Moorea reefs. Considering the 616 spectra, the SSW analysis identified 16 non-redundant wavelengths ( $\mathrm{p}<0.05$ ), including 6 above $600 \mathrm{~nm}$ (Table 3); overall classification accuracy was 92.0\% (Table 4). Considering only the Rangiroa spectra, the SSW analysis identified 11 nonredundant wavelengths optimized for the atoll communities; overall accuracy was $94.1 \%$ (Table 4). Using the 616 spectra, the reconnaissance achieved using only the 2 first linear discriminant functions is presented in Fig. 5. The groups of the brown, green and coralline Hydrolithon onkodes algae are clearly separated. The complex Rhodolithes/Anabaena torulosa is intermediate between the green algae and the cluster formed by dead structures, pavement and rubbles. The red algae stretch between $H$. onkodes and the cluster pavement/rubble. Other linear functions help to discriminate between the main clusters in Fig. 5. For instance, the group of brown algae (Padina boryana, Turbinaria ornata, Sargassum spp. and Dictyota spp.) can be separated using different LDFs (data not shown).

\section{Airborne $\boldsymbol{R}_{r s}$ spectra and community-level discrimination}

The parameters used to transform $L_{t}$ into $R_{r s}$ are provided in Table 5 for Moorea. They are of the same magnitude for Rangiroa (not shown). The range and spectral shape between 400 and $700 \mathrm{~nm}$ of the various correcting variables provided by the models are of minor influence. Spectral binning to match the CASI bandwidths also attenuates effects that could have an influence at higher spectral resolution. The small influence of the atmosphere is explained by the low altitude of the flight. Sky-reflected radiance is also a very small factor in consideration of the larger amplitude of the shallow targets (0 to $3 \mathrm{~m}$ ). This warrants further sensi-
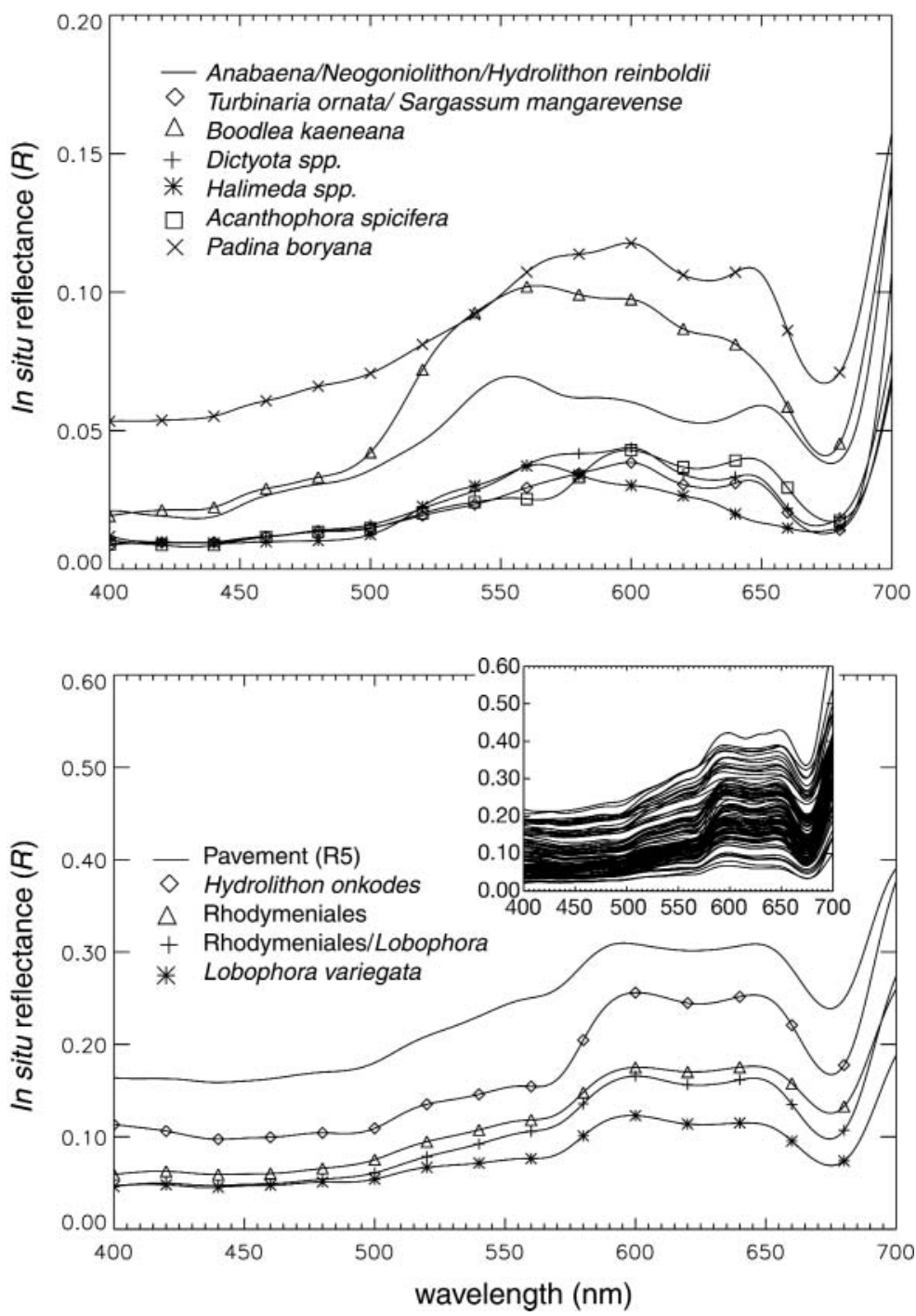

Fig. 4. Mean in situ reflectance spectra for some dominant algae in Table 2. Top: Moorea (see also Andréfouët et al. 2001 for rubble, pavement and turf spectra); bottom: Rangiroa. Note different ordinate scales. Each alga appears well separated by mean reflectances, but inset (representing all Rangiroa samples) highlights actual continuum of reflectance 
Table 3. Wavelengths (nm) identified by stepwise selection of wavelengths (SSW) for in situ and CASI reflectance, for Moorea and Rangiroa. Last 2 columns show common wavelengths for in situ and CASI measurements

\begin{tabular}{|c|c|c|c|c|c|}
\hline \multicolumn{2}{|c|}{ In situ reflectance } & \multicolumn{2}{|c|}{ CASI reflectance } & \multicolumn{2}{|c|}{ Common wavelengths } \\
\hline $\begin{array}{l}\text { Moorea + } \\
\text { Rangiroa }\end{array}$ & $\begin{array}{l}\text { Rangiroa } \\
\text { only }\end{array}$ & Moorea & Rangiroa & (Moorea) & Rangiroa \\
\hline 699 & 700 & 691 & 699 & 645 & 682 \\
\hline 688 & 684 & 675 & 694 & 630 & 665 \\
\hline 664 & 664 & 660 & 688 & 584 & 614 \\
\hline 644 & 658 & 645 & 682 & 554 & 592 \\
\hline 628 & 612 & 630 & 671 & 539 & 580 \\
\hline 606 & 594 & 615 & 665 & 450 & 535 \\
\hline 584 & 578 & 599 & 654 & 406 & \\
\hline 572 & 534 & 584 & 648 & & \\
\hline 554 & 456 & 569 & 614 & & \\
\hline 540 & 434 & 554 & 608 & & \\
\hline 518 & 400 & 539 & 592 & & \\
\hline 500 & & 524 & 580 & & \\
\hline 475 & & 509 & 568 & & \\
\hline 450 & & 480 & 546 & & \\
\hline 432 & & 465 & 535 & & \\
\hline \multirow[t]{5}{*}{405} & & 450 & 529 & & \\
\hline & & 435 & 473 & & \\
\hline & & 406 & 462 & & \\
\hline & & & 440 & & \\
\hline & & & 418 & & \\
\hline
\end{tabular}

Table 4. Overall accuracy (\%) achieved in different configurations (full set and subset of wavelengths) for each site

\begin{tabular}{|lcccc|}
\hline \multirow{2}{*}{ Configuration } & \multicolumn{2}{c}{ Moorea } & \multicolumn{2}{c|}{ Rangiroa } \\
& in situ & CASI & in situ & CASI \\
\hline No. of & 14 & 16 & 5 & 14 \\
classes & species & communities & species & communities \\
Full set of & $92.0 \%$ & $90.9 \%$ & $94.1 \%$ & $83.5 \%$ \\
wavelengths & $(16$ bands $)$ & $(18$ bands $)$ & $(11$ bands $)$ & $(20$ bands $)$ \\
Subset common & $85.9 \%$ & $86.1 \%$ & $93.3 \%$ & $76.4 \%$ \\
wavelengths & $(7$ bands $)$ & $(7$ bands $)$ & $(6$ bands $)$ & $(6$ bands $)$ \\
& & & & \\
\hline
\end{tabular}

tivity analysis, but it is unlikely that the influence of sky-reflected light will be as critical as it is for deep-water environments (Mobley 1999, Hu \& Carder 2002).

$R_{r s}$ spectra are provided in Fig. 6 . Moorea spectra had shapes typical of shallow underwater targets due to water attenuation above $570 \mathrm{~nm}$, while Rangiroa spectra showed very little water attenuation except for the pavement (R6) submerged at $\sim 50 \mathrm{~cm}$ depth. Elsewhere, the communities were subsurface, which is typical of Tuamotu atolls' outer reef flats. Except for communities with a large proportion of sand or bare pavement, the spectra peak at $0.03 \mathrm{sr}^{-1}$ around $575 \mathrm{~nm}$. The shape of the deepwater $R_{r s}$ spectrum (Fig. 7) is correct (e.g. Mobley 1999), with the chl a fluorescence peak at $680 \mathrm{~nm}$ visible on a log-scale plot. The range of values seems a bit high for Moorea, but is in agreement with spectra published for the same location (Maritorena \& Guillocheau 1996). Rangiroa $R_{r}$ spectra, computed at higher spectral resolution than Moorea, suggest a lack of accurate correction since atmospheric absorption features are visible. These artifacts can be attributable to a calibration problem (especially in the blue) or an underestimation of the atmospheric path radiance (also more critical in the blue).

Table 5. Coefficients used to convert CASI total radiance to remote-sensing reflectance for Moorea image. See 'Materials and methods - Acquisition and processing of airborne CASI data' for parameter explanations

\begin{tabular}{|lcccccc|}
\hline $\begin{array}{l}\text { Wavelength } \\
(\mathrm{nm})\end{array}$ & $t$ & $\begin{array}{c}E_{d s} \\
\mathrm{~W} \mathrm{~m} \mathrm{~nm}^{-1}\end{array}$ & $\begin{array}{c}E_{d} \\
\mathrm{~W} \mathrm{~m}^{-2} \mathrm{~nm}^{-1}\end{array}$ & $r$ & $\begin{array}{c}L_{\text {atm }} \\
\mathrm{W} \mathrm{m}^{-1} \mathrm{~nm}^{-1} \mathrm{sr}^{-1}\end{array}$ \\
\hline 406 & 0.992 & 0.301 & 0.963 & 4.086 & 0.00305 & $\mathrm{~W} \mathrm{~m}^{-2} \mathrm{~nm}^{-1} \mathrm{sr}^{-1}$ \\
421 & 0.993 & 0.283 & 1.004 & 4.206 & 0.00271 & 0.00146 \\
435 & 0.993 & 0.265 & 1.032 & 4.309 & 0.00242 & 0.00134 \\
450 & 0.994 & 0.289 & 1.230 & 4.430 & 0.00251 & 0.00132 \\
465 & 0.995 & 0.270 & 1.253 & 4.607 & 0.00229 & 0.00117 \\
480 & 0.995 & 0.249 & 1.250 & 4.706 & 0.00202 & 0.00105 \\
494 & 0.996 & 0.227 & 1.225 & 4.757 & 0.00176 & 0.00095 \\
509 & 0.996 & 0.210 & 1.219 & 4.813 & 0.00156 & 0.00087 \\
524 & 0.996 & 0.193 & 1.200 & 4.875 & 0.00137 & 0.00079 \\
539 & 0.996 & 0.183 & 1.216 & 4.950 & 0.00126 & 0.00074 \\
554 & 0.997 & 0.170 & 1.203 & 5.017 & 0.00112 & 0.00068 \\
569 & 0.997 & 0.158 & 1.185 & 5.035 & 0.00102 & 0.00063 \\
584 & 0.997 & 0.143 & 1.136 & 5.043 & 0.00092 & 0.00057 \\
599 & 0.997 & 0.133 & 1.112 & 5.051 & 0.00084 & 0.00052 \\
615 & 0.997 & 0.128 & 1.134 & 5.059 & 0.00076 & 0.00051 \\
630 & 0.998 & 0.119 & 1.106 & 5.068 & 0.00069 & 0.00047 \\
645 & 0.998 & 0.110 & 1.066 & 5.075 & 0.00062 & 0.00043 \\
660 & 0.998 & 0.100 & 1.020 & 5.078 & 0.00056 & 0.00039 \\
675 & 0.998 & 0.097 & 1.032 & 5.078 & 0.00052 & 0.00038 \\
691 & 0.998 & 0.081 & 0.904 & 5.078 & 0.00044 & 0.00032 \\
\hline
\end{tabular}




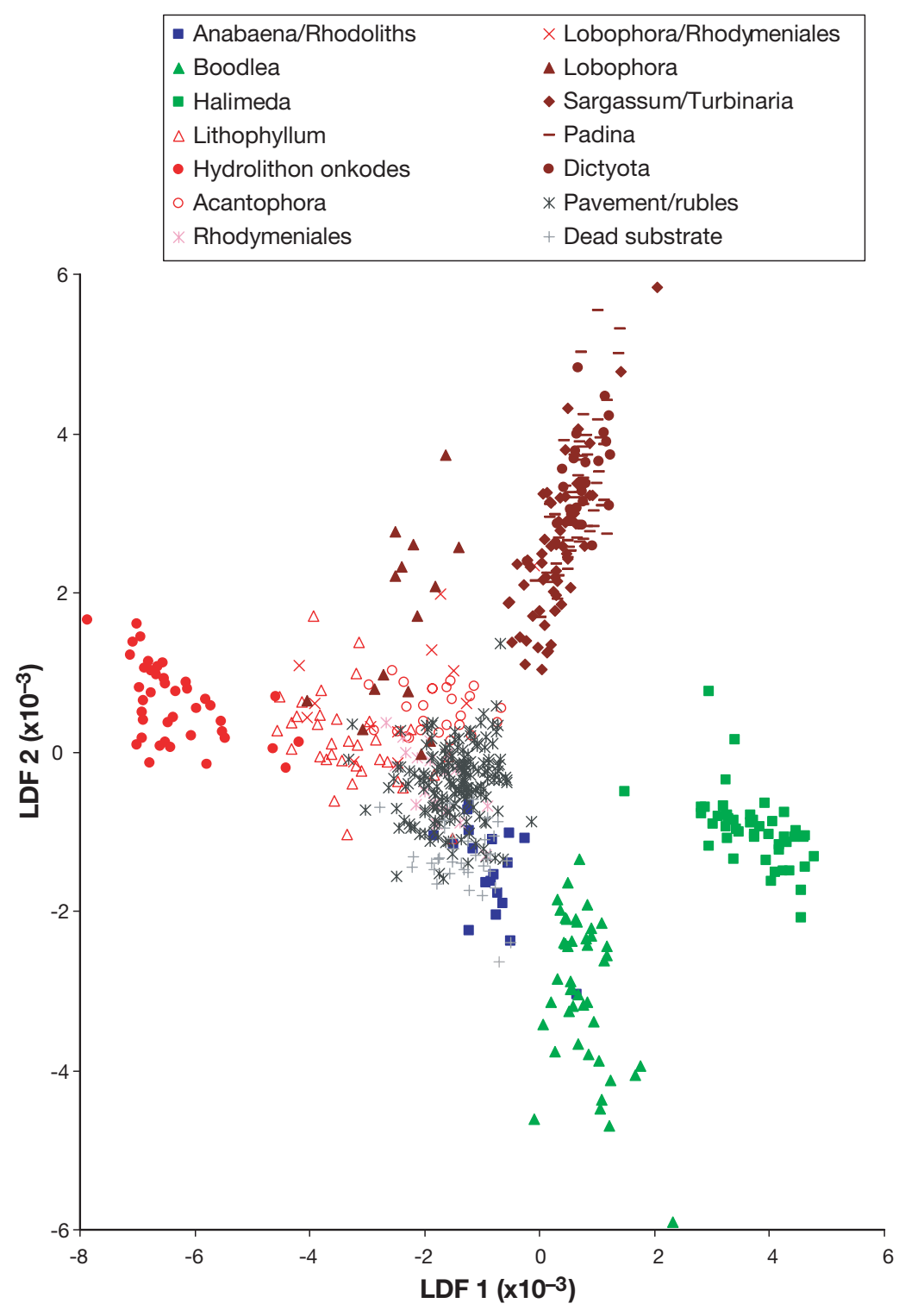

Fig. 5. Moorea and Rangiroa: 616 in situ reflectance spectra projected in plane formed by Linear Discriminant Functions (LDFs) 1 and 2, computed from 16 non-redundant wavelengths in Table 3. Full species names in Table 1

Comparisons between ranking of in situ reflectance and remote-sensing reflectance reveal different patterns (Figs. 4 \& 6). For instance, Lobophora variegata is at the lowest range of in situ reflectance as a species, but is intermediate in $R_{r s}$ as a community (R3). The opposite is found for Hydrolithon onkodes. This reflects the influence of background at the community scale. For instance, the $L$. variegata-dominated community (R2, Table 1) is brightened by the pavement in the background, while Community R1 (Table 1) is entirely covered by its dominant species $H$. onkodes.

For Moorea and Rangiroa CASI data, 18 and 20 wavelengths were identified respectively by SSW
(Table 3), providing classification accuracies of 90.9 and $83.5 \%$ respectively (Table 4 ). Discrimination of the 16 algae communities of Moorea is presented using the 3 first linear functions (Figs. $8 \& 9$ ). The third function is critical for separating the MB2 back-crest coral/algae assemblage, rich in corals ( $25 \%$ cover $)$, Turbinaria ornata and Sargassum mangarevense, from other locations dominated only by the same algae, such as the tops of large dead patches. In Rangiroa, all groups were clearly differentiated using only the first 2 linear discriminant functions. The apparent lower accuracy $(83.5 \%)$ is explained by the fact that we have kept each ground-truthing site separate. Thus, similar communities overlapped (e.g. the 3 Hydrolithon onkodes sites: Fig. 10), and decreased the overall accuracy. The plots also show that mixed classes fall between the pure classes. This result encourages unmixing algorithms using spectral endmembers.

\section{Robustness of spectral separability between species and community levels}

Using only the subset of common non-redundant wavelengths identified in both in situ and CASI measurements, we observed excellent discrimination and classification accuracy between the algal groups at both sites. For Rangiroa, these common bands were centered at $\{682,665,614,592,580,535 \mathrm{~nm}\}$. The overall accuracy of CASI spectra ranged from $83.5 \%$ down to $76.4 \%$ (Table 4). For Moorea, the key wavebands were centered at $\{645,630,584$, $554,539,450,406 \mathrm{~nm}\}$. Overall accuracy of CASI spectra decreased from $90.9 \%$ down to $86.1 \%$ (Table 4 ). The discrimination remained visually excellent for Rangiroa communities using the first 2 linear discriminant functions (Fig. 11 and Table 3). Conversely, 8 of the 16 Moorea communities suffered accuracy loss. The most significant degradation was for the MB2 back crest coral/algae assemblage (Fig. 2) with a loss of $15 \%$ accuracy, while the MB3 rhodolith patch (Fig. 2) decreased from $100 \%$ accuracy down to $66 \%$ (Fig. 12).

\section{DISCUSSION}

We used species-level spectra only for algae, and considered communities dominated by the same species. Under these conditions, our results suggest that 

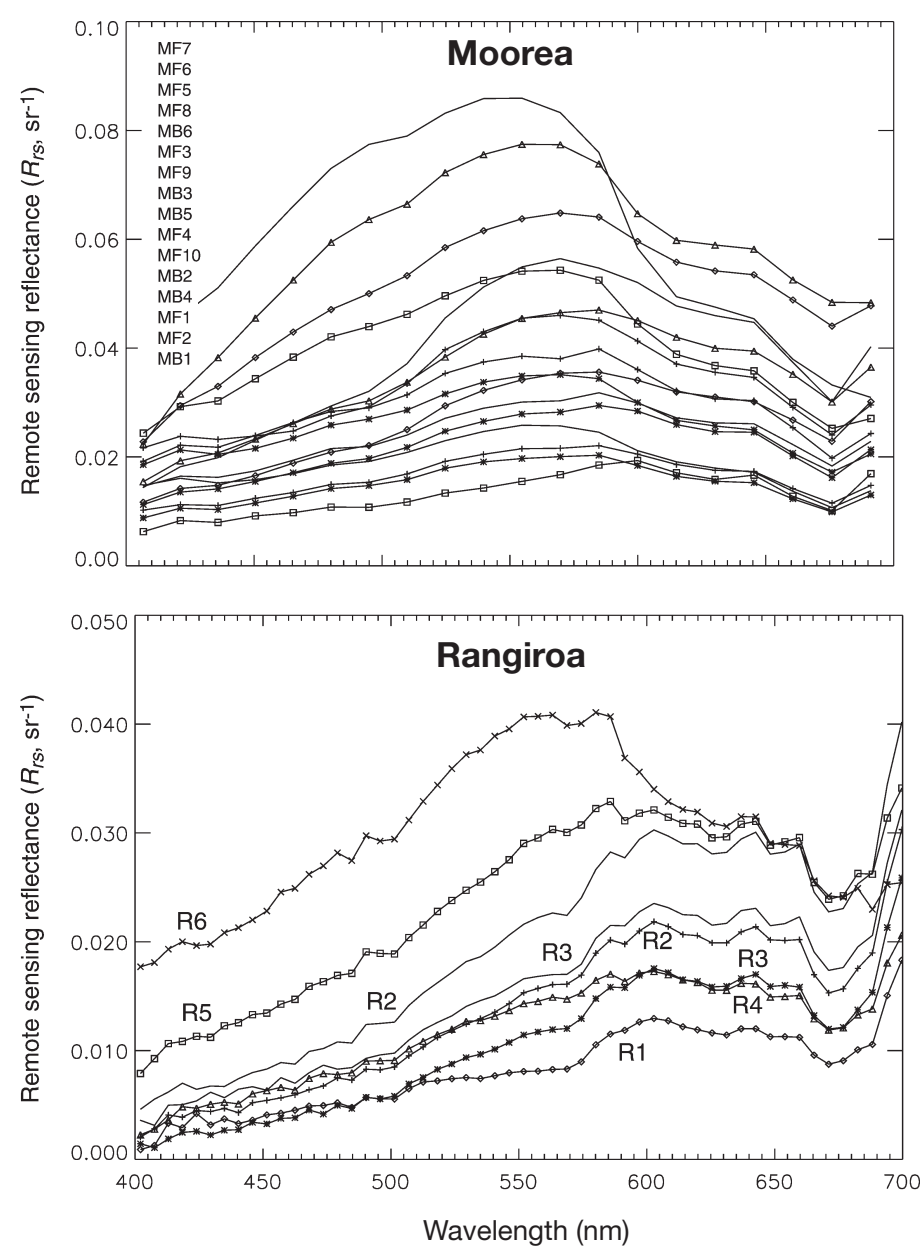

Fig. 6. Average CASI remote-sensing reflectance $\left(R_{r s}\right)$ spectra for each community in Moorea (top graph) and Rangiroa (bottom graph); zones labeled as in Table 1. For Moorea, zones are listed by decreasing $R_{r s}$ at $524 \mathrm{~nm}$

utilizing species-level reflectance to define wavebands and apply them directly for community-level discrimination using $R_{r s}$ is effective, despite increased spatial heterogeneity and spectral mixing. Classification accuracies decrease when using fewer wavebands, but the rates remain excellent (Table 4 ).

The major caveat to generalizing our results would be the importance of the depth factor. Rangiroa results can be generalized with confidence to most Pacific atoll-rim communities, since coralline pavement communities occur mostly in shallow waters. On the other hand, results for more ubiquitous Moorea communities would be more questionable in deeper water. Several of the spectral bands identified at Moorea were longer than $600 \mathrm{~nm}$ and these would be less informative in water depths greater than few meters. For deeper waters, only wavebands that are still informative at depth could be used. Some degradation in the classification results could thus be expected, but Hochberg \&

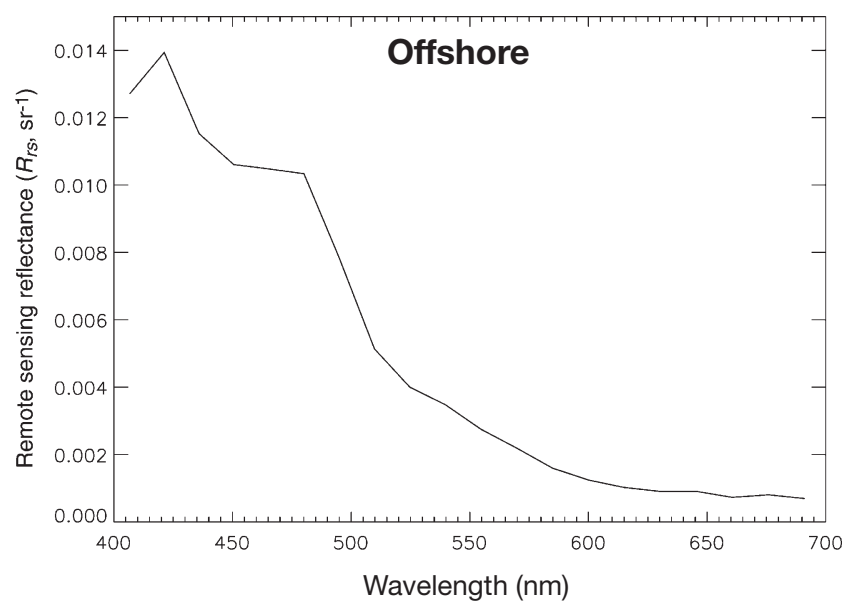

Fig. 7. Remote-sensing reflectance $\left(R_{r s}\right)$ spectrum of deep, clear-blue waters offshore Moorea (see also Maritorena \& Guillocheau 1996 for spectra from same location)

Atkinson (2000) showed that even with only 4 bands below $584 \mathrm{~nm}$, results were acceptable, although they tested only the level of very ecologically broad communities (coral, algae and sediment). We emphasize that, despite the lack of bathymetric correction of the $R_{r S}$ spectra, spectral scaling is effective, indicating that accurate bathymetric correction of $R_{r s}$ data in the 0 to $3 \mathrm{~m}$ range of depth is not strictly necessary when using $R$ data. However, beyond $3 \mathrm{~m}$, it is likely that water correction will be required to improve the classification results (Purkis \& Paterkamp 2004). Nevertheless, shallow-reef flats are very extensive in the Indo-Pacific areas. They represent, in terms of surface area, most of the productive coral reef system at many locations. In addition, they are likely to be more vulnerable to storms, bleaching, pollution or human activities. Therefore, they are prime targets for remote-sensing investigations, and our conclusion that depth correction can be omitted for these areas when using hyperspectral data is of potential importance.

Working at the ecological end-member level (corals, algae, sediments) has many conceptual merits. For instance, comparisons between sites are theoretically easier, since the end-members are ubiquitous. However, this approach, by systematically breaking the ecological system into 'atomic' units, may hide entities that have an ecological meaning only as a whole. For instance, modes in the inorganic or organic productivity of coral reefs have been expressed by Kinsey (1985) in terms of communities. Also, a large lone brown Porites sp. coral head, with some brown algae (Turbinaria ornata) on top, on a sandy bottom covering half a pixel may have the same mixed and unmixed signature as a pixel comprised of $50 \%$ sand and $50 \%$ numerous small rocks covered by the same algae and 
Fig. 8. Moorea: 230 CASI remote-sensing reflectance projected in plane formed by LDFs 1 and 2, computed from 18 non-redundant wavelengths (Table 3); zones labeled as in Table 1. Poorly classified clusters correspond to mixed brown algae communities (e.g. coral-brown algae or turfbrown algae), and are close to end-member MB1 (algal crest, covered by brown algae Turbinaria ornata-Sargassum mangarevense) (see also Fig. 9). Full species names in Table 1 ; cyano: cyanobacteria

Fig. 9. Moorea: 230 CASI remote-sensing reflectance spectra projected in plane formed by LDFs 1 and 3, computed from 18 nonredundant wavelengths (Table 3); zones labeled as in Table 1. LDF 3 allows discrimination within mixed brown algae communities (see Fig. 8). Note separation achieved for MB2 ( $\diamond$ ), area with highest coral cover on Moorea barrier reef; circled data points: groups poorly separated by LDFs 1 and 2 (Fig. 8). Full species names in Table 1; cyano: cyanobacteria
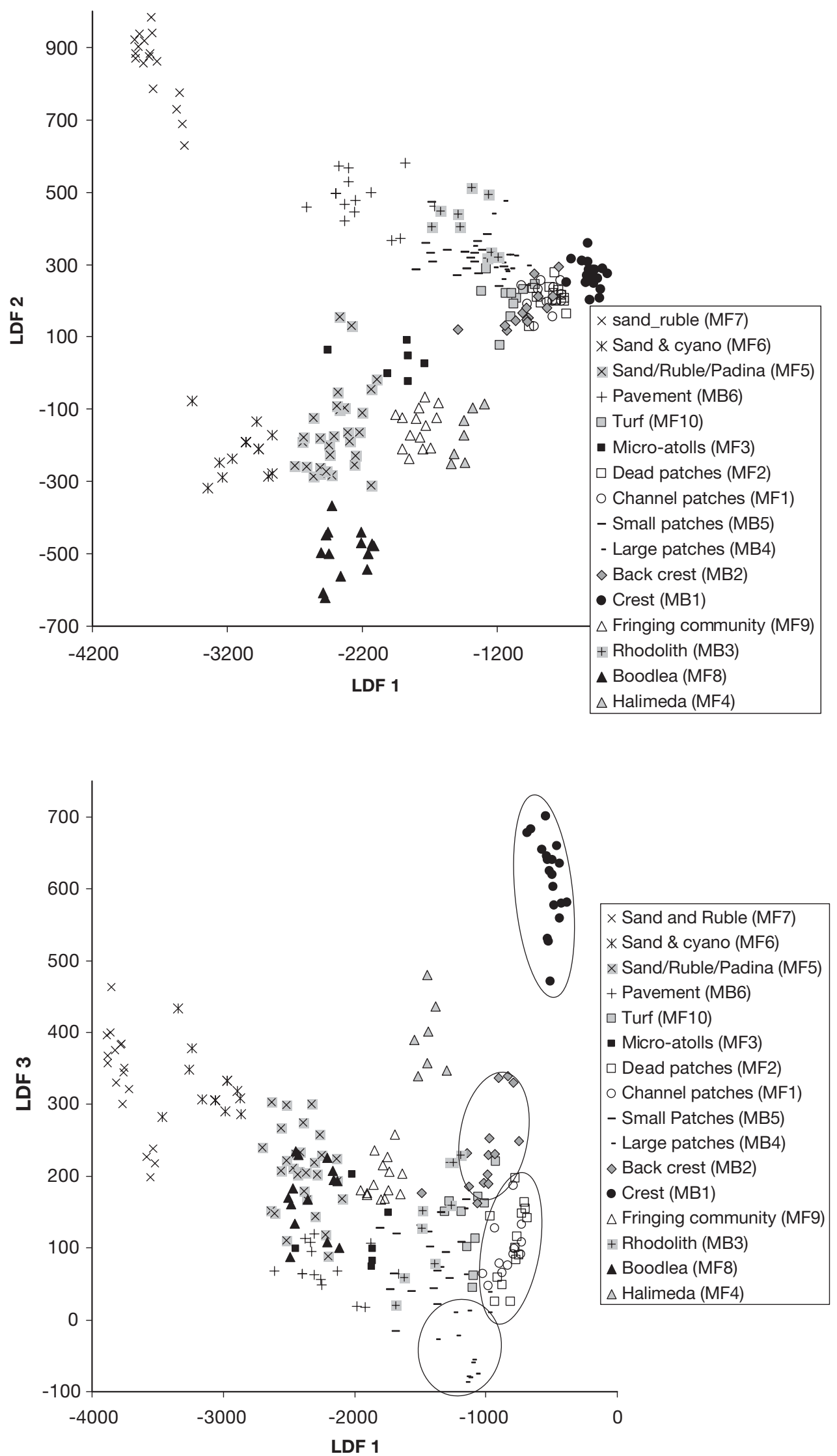

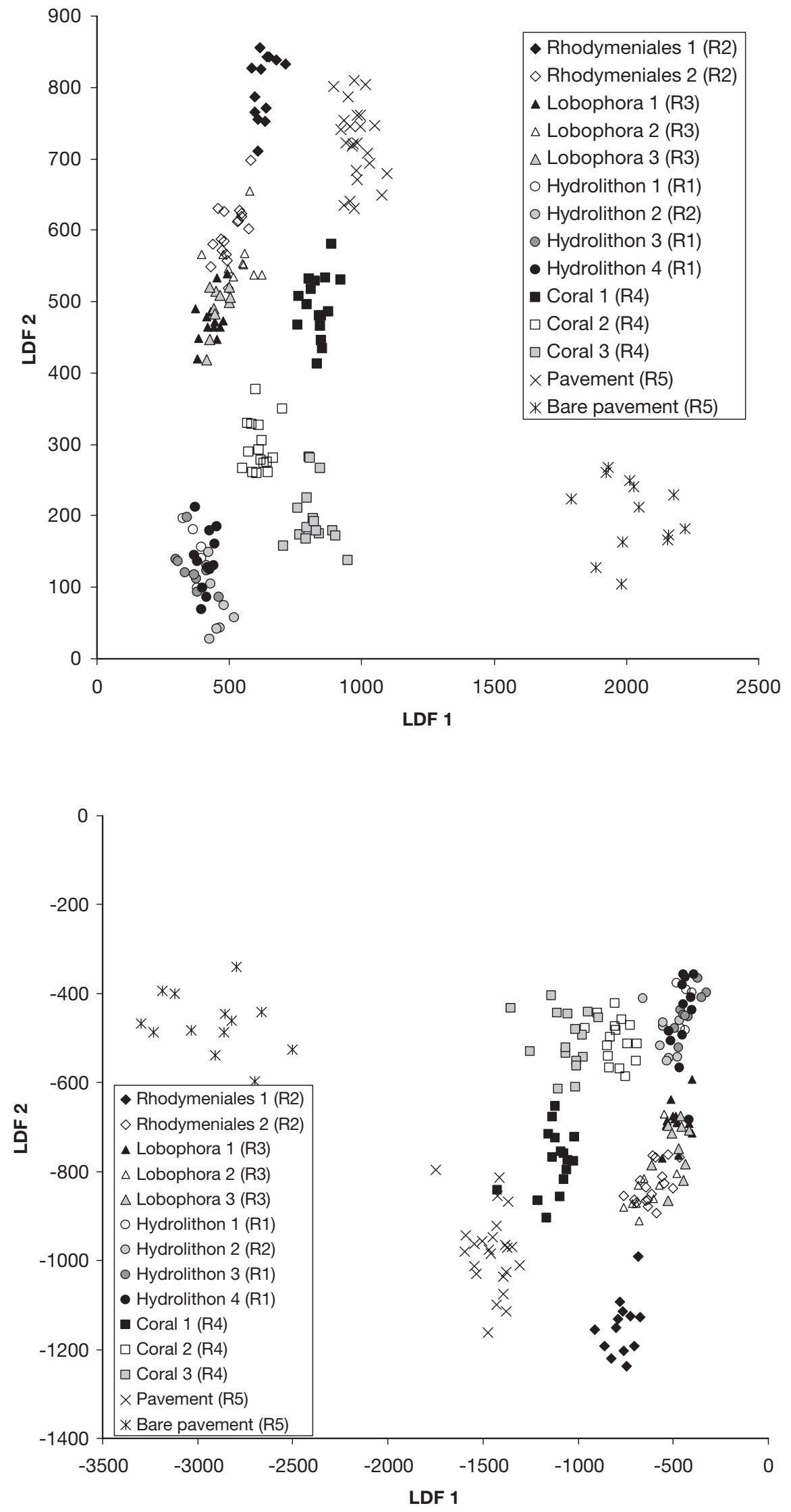

Fig. 10. Rangiroa: 182 CASI remote-sensing reflectance spectra projected in plane formed by LDFs 1 and 2, computed from 20 non-redundant wavelengths (Table 3). Zones and full species names in Table 1
Fig. 11. Rangiroa: 182 CASI remote-sensing reflectance spectra projected in plane formed by LDFs 1 and 2, computed from 6 non-redundant wavelengths (Table 3). Zones and full species names in Table 1 
Fig. 12. Moorea: 230 CASI remote-sensing reflectance spectra projected in plane formed by LDFs 1 and 2, computed from 7 non-redundant wavelengths (Table 3). Zones and full species names in Table 1

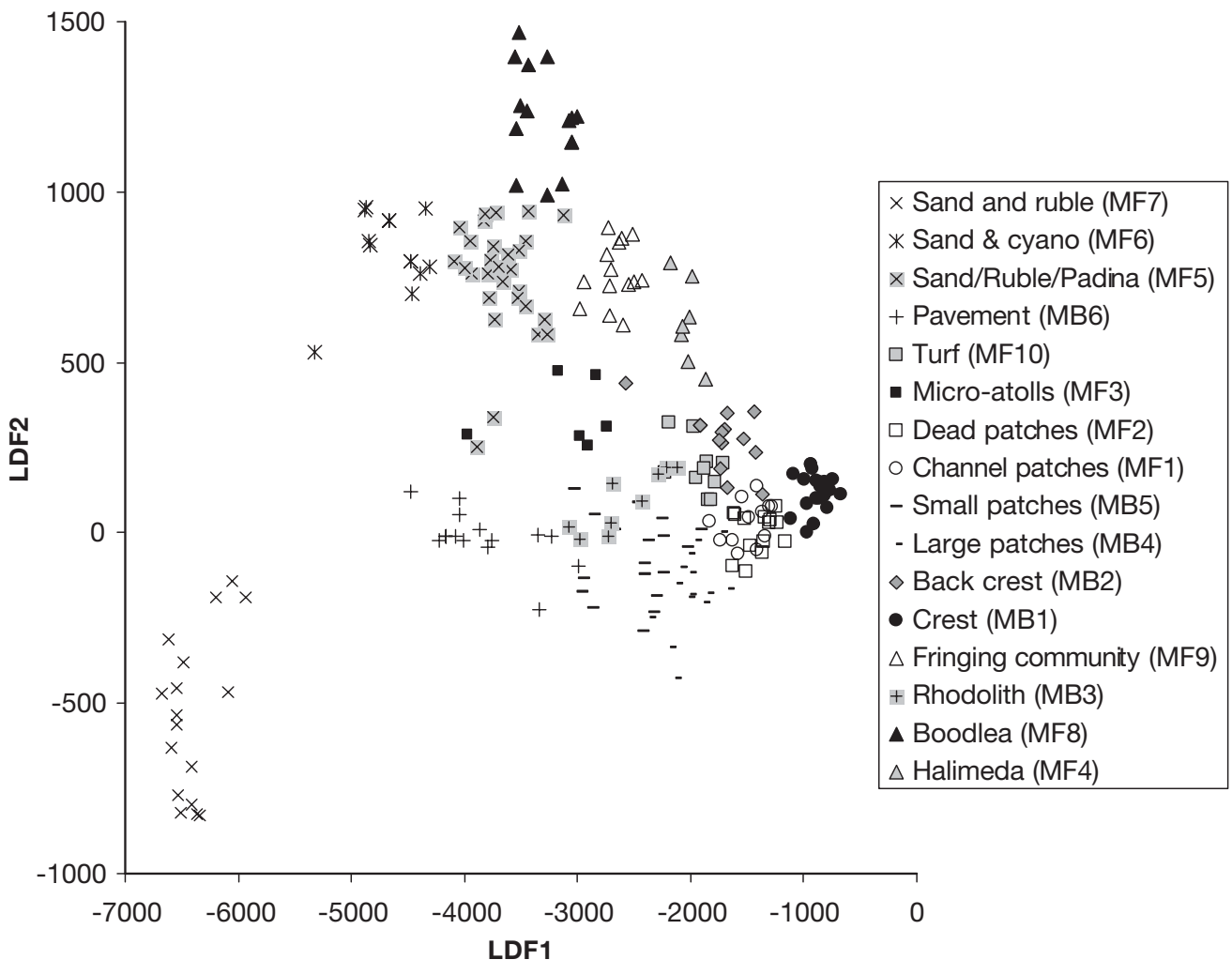

We consider this a pilot study. It is an objective confirmation that it is possible to scale from species-level to community-level algorithms in the real world using real data, not simulations. However, similar tests need to be made. Inter-site comparisons taking their specific features into account are necessary to fully understand which methods work and what results can be consistently expected. We recently compared habitat classification results for 10 different sites representative of reef morphology and habitat types worldwide, using 4 m-resolution, spaceborne, multispectral data ('IKONOS images'). The pooled results show clear trends in accuracy, but local specificities are important and modulate the general trends (Andréfouët et al. 2003). Similar strategies should be applied for community-scale assessments using hyperspectral measurements. Nevertheless, the current study has demonstrated that using spectral libraries at the organism scale to interpret airborne imagery at the community scale is likely to provide accurate classification results, when the main species of the area covered by the imagery are present in in situ data.

\section{CONCLUSION}

Our goals were 2-fold: (1) operational remotesensing application, to test the robustness of optical 
criteria of separability between 2 ecological and spatial scales; (2) to increase our knowledge on the spectral discrimination of tropical algae species and communities from 2 French Polynesian reefs with very different structures. This study is the first to explicitly address the problem of spatial scaling of spectral measurements in shallow aquatic environments. Even if our results are considered local, they clearly suggest that it is possible and effective to generalize optical criteria from species level to community level, and thereby refine the design of hyperspectral missions, whether airborne or spaceborne. Rather than acquiring fullspectrum data, keying on pre-selected wavebands will provide better image signal-to-noise ratios and allow increases in spatial resolution. Similar to the globalscale comparative studies recently achieved at the species-level using in situ measurements (Hochberg et al. 2003) and at the habitat level using satellite images (Andréfouët et al. 2003), we suggest that a worldwide well-stratified study targeting the current 'missing link' (i.e. community scale) using airborne data is required to complete our knowledge of the optical properties of coral reefs. With this knowledge, the design of multi-scale space missions aimed at surveying and understanding coral reef functions and status will be greatly improved.

Acknowledgements. CASI images were available via Herb Ripley (Hyperspectral Data), thanks to the extraordinary generosity of Prince Khaled bin Sultan bin Abdulaziz of Saudi Arabia. Jean Jaubert and John R. Chisholm, Observatoire Océanographique Européen, Monaco, coordinated and supported the CASI flights. Laura Roy (HDI) pre-processed the CASI data and provided information on the calibration of the sensor. Spectral processing was partly funded by NASA awards NAG5-10908, NAG-10738, NAG5-7513, NAG5-5276 to S.A., C.H., and M.J.A.; and NOAA NA07-OA0571 to M.J.A. This is HIMB contribution No. 1189 IMaRS contribution No. 078.

\section{LITERATURE CITED}

Aas E, Hokedal J (1999) Reflection of spectral sky irradiance on the surface of the sea and related properties. Remote Sens Environ 70:181-190

Andréfouët S, Payri C (2001) Scaling-up carbon and carbonate metabolism in coral reefs using in situ and remote sensing data. Coral Reefs 19:259-269

Andréfouët S, Muller-Karger F, Hochberg E, Hu C, Carder K (2001) Change detection in shallow coral reef environments using Landsat 7 ETM+ data. Remote Sens Environ 79:150-162

Andréfouët S, Kramer P, Torres-Pulliza D, Joyce KE and 12 others (2003) Multi-sites evaluation of IKONOS data for classification of tropical coral reef environments. Remote Sens Environ 88:128-143

Andréfouët S, Zubia M, Payri C (2004) Mapping and biomass estimation of the invasive brown algae Turbinaria ornata (Turner) J. Agardh and Sargassum mangarevense (Grunow) Setchell on heterogeneous Tahitian coral reefs using 4-meter resolution IKONOS satellite data. Coral Reefs 23: 26-38

Atkinson MJ, Lucey PG, Taylor GJ, Porter J, Dollar S, Andréfouët S (2001) CRESPO: Coral Reef Ecosystem SpectroPhotometric Observatory. Concept study report to the University Earth System Science Program, National Aeronautics and Space Administration. University of Hawaii

Babey SK, Soffer RJ (1992) Radiometric calibration of the compact airborne spectrographic imager (CASI). Can J Remote Sens 18:233-242

Beach KS, Borgeas HB, Nishimura NJ, Smith CM (1997) In vivo absorbance spectra and the ecophysiology of reef macroalgae. Coral Reefs 16:21-28

Clark CD, Mumby PJ, Chisholm JRM, Jaubert J, Andréfouët S (2000) Spectral discrimination of coral mortality states following a severe bleaching event. Int J Remote Sens 21: 2321-2327

Dekker AG, Brando VE, Anstee JM, Pinnel N and 7 others (2001) Imaging spectrometry of water. In: Van der Meer FD, De Jong SM (eds) Imaging spectrometry. Kluwer, Dordrecht, p 307-359

Fyfe S (2003) Spatial and temporal variation in spectral reflectance: are seagrass species spectrally distinct? Limnol Oceanogr 48:464-479

Gattuso JP, Payri CE, Pichon M, Delesalle B, Frankignoulle M (1997) Primary production, calcification, and air-sea $\mathrm{CO}_{2}$ fluxes of a macro-algal-dominated coral reef community (Moorea, French Polynesia). J Phycol 33:729-738

Gregg WW, Carder KL (1990) A simple spectral solar irradiance model for cloudless maritime atmospheres. Limnol Oceanogr 35:1657-1675

Hedley JD, Mumby PJ (2002) Biological and remote sensing perspectives of pigmentation in coral reef organisms. Adv Mar Biol 43:277-317

Hedley JD, Mumby PJ, Joyce KE, Phinn SR (2004) Spectral unmixing of coral reef benthos under ideal conditions. Coral Reefs 23:60-73

Hochberg EJ, Atkinson MJ (2000) Spectral discrimination of coral reef benthic communities. Coral Reefs 19:164-171

Hochberg EJ, Atkinson MJ (2003) Capabilities of remote sensors to classify coral, algae and sand as pure and mixed spectra. Remote Sens Environ 85:174-189

Hochberg EJ, Atkinson MJ, Andréfouët S (2003) Spectral reflectance of coral reef community-types worldwide and implications for coral reef remote sensing. Remote Sens Environ 85:159-173

Hu C, Carder K (2002) Atmospheric-correction for airborne sensors: comment on a scheme used for CASI. Remote Sens Environ 79:134-137

Jakubauskas M, Kindscher K, Fraser A, Debinskis D, Price K (2000) Close-range remote sensing of aquatic macrophyte vegetation cover. Int J Remote Sens 21:3533-3538

Karpouzli E, Malthus T, Place C (2004) Hyperspectral discrimination of coral reef benthic communities in Western Caribbean. Coral Reefs 23:141-151

Kinsey DW (1985) Metabolism, calcification and carbon production. I. System level studies. Proc 5th Int Coral Reef Congr 4:505-526

Kutser T, Dekker A, Skirving W (2003) Modelling spectral discrimination of Great Barrier Reef benthic communities by remote sensing instruments. Limnol Oceanogr 48:497-510

Long BG, Poiner IR, Harris AN (1993) Method of estimating the standing stock of Trochus niloticus incorporating LANDSAT satellite data, with application to the Trochus resources of the Bourke Isles, Torres Strait, Australia. Mar Biol 115:587-593

Louchard E, Reid P, Stephens F, Davis C, Leathers R, Downes 
$\mathrm{T}$ (2003) Optical remote sensing of benthic habitats and bathymetry in coastal environments at Lee Stocking Island, Bahamas: a comparative spectral classification approach. Limnol Oceanogr 48:511-521

Lubin D, Li W, Dustan P, Mazel CH, Stamnes K (2001) Spectral signatures of coral reefs: features from space. Remote Sens Environ 75:127-137

Maritorena S, Guillocheau N (1996) Optical properties of water and spectral light absorption by living and nonliving particles and by yellow substances in coral reef waters of French Polynesia. Mar Ecol Prog Ser 131:245-255

Maritorena S, Morel A, Gentili B (1994) Diffuse reflectance of oceanic shallow waters: influence of water depth and bottom albedo. Limnol Oceanogr 39:1689-1703

Minghelli-Roman A, Chisholm JRM, Marchioretti M, Jaubert JM (2002) Discrimination of coral reflectance spectra in the Red Sea. Coral Reefs 21:307-314

Mobley CD (1999) Estimation of the remote-sensing reflectance from above-water surface measurements. Appl Optics 38:7442-7455

Mumby PJ, Green EP, Clark CD, Edwards AJ (1997) Coral reef habitat mapping: how much detail can remote sensing provide? Mar Biol 130:193-202

Mumby PJ, Chisholm JRM, Clark CD, Hedley JD, Jaubert J (2001) A bird's-eye view of the health of coral reefs. Nature 413:36

Myers MR, Hardy JT, Mazel CH, Dustan P (1999) Optical spectra and pigmentation of Caribbean reef corals and macroalgae. Coral Reefs 18:179-186

Payri CE (1987) Zonation and seasonal variation of the commonest algae on Tiahura reef (Moorea Island, French Polynesia). Bot Mar 30:141-149

Payri CE (1997) Hydrolithon reinboldii rhodolith distribution, growth and carbon production of a French Polynesian reef. Proc 8th Int Coral Reef Symp 1:755-760

Payri CE, De N'Yeurt AR (1998) A revised checklist of Polynesian benthic marine algae. Aust Syst Bot 10:867-910

Editorial responsibility: Charles Birkeland (Contributing Editor), Honolulu, Hawaii, USA
Payri C, De N'Yeurt A, Orempuller J (2000) Algae of French Polynesia. Au Vent des Iles, Papeete, Tahiti

Payri CE, Maritorena S, Bizeau C, Rodiere M (2001) Photoacclimation in the tropical coralline alga Hydrolithon onkodes (Rhodophyta, Corallinaceae) from a French Polynesian reef. J Phycol 37:223-234

Pichon M (1985) Organic production and calcification in some coral reefs of French Polynesia. Proc 5th Int Coral Reef Congr 6:173-177

Purkis S, Pasterkamp R (2004) Integrating in situ reef top reflectance spectra with Landsat TM imagery to aid shallow tropical benthic habitat mapping. Coral Reefs 23:5-20

Rencher A (1995) Methods of multivariate analysis. John Wiley, New York

Russel DJ, Balazs GH (1994) Colonization by the alien marine alga Hypnea musciformis (Wulfen) J. Ag. (Rhodophyta: Gigartinales) in the Hawaiian islands and its utilization by the green turtle, Chelonia mydas L. Aquat Bot 47:53-60

Stiger V, Payri C (1997) Strategies of reef invasion by two brown algae in Tahiti (French Polynesia): reproduction, dispersion, competition. Phycologia 36:414-415

Toole DA, Siegel DA, Menzies DW, Neumann MJ, Smith RC (2000) Remote-sensing reflectance determinations in the coastal ocean environment: impact of instrumental characteristics and environmental variability. Appl Optics 39: 456-469

Vermote EF, Tanre D, Deuze JL, Herman M, Morcrette JJ (1997) Second simulation of the satellite signal in the solar spectrum, 6S: an overview. IEEE (Inst Electr Electron Eng) Trans Geosci Remote Sens 35:675-686

Wittlinger S, Zimmerman R (2000) Hyperspectral remote sensing of subtidal macroalgal assemblages in optically shallow waters. Proc Ocean Optic XV, Monaco, CDROM

Yamano H, Tamura M, Kunii Y, Hidaka M (2002) Hyperspectral remote sensing and radiative transfer simulation as a tool for monitoring coral reef health. J Mar Technol Soc 36:4-13

Submitted: April 11, 2003; Accepted: June 9, 2004

Proofs received from author(s): November 15, 2004 